\title{
Variation by age group and seasonality at diagnosis of childhood IDDM in Europe
}

\author{
C. Lévy-Marchal, C.Patterson, A.Green on behalf of the EURODIAB ACE Study Group*
}

Summary Recent data provided by the EURODIAB ACE study group have confirmed wide variation in the incidence of insulin-dependent diabetes mellitus (IDDM) across Europe. The aim of this report is to compare age-specific incidence and seasonality at clinical onset of IDDM between study regions. Using a uniform methodology, the EURODIAB ACE framework ascertained 3,168 newly-diagnosed cases of IDDM in children under the age of 15 years during 1989-1990. Eighteen percent of the cases were age $0-4$ years at diagnosis, $34 \%$ were age $5-9$ years and $48 \%$ were age $10-14$ years. Poisson regression analysis suggested that there were highly significant statistical differences in incidence between the three age groups and between the 24 regions. Although incidence rates in the $0-4$ year and 5-9 year age groups varied from region to region in a similar fashion, the pattern of variation in the older age group was different. Seasonality of diagnosis conformed to a sinusoidal model with a peak occurring in winter, a feature which was consistently observed in both sexes and in all age groups. However, a statistically significant heterogeneity in the seasonal distribution was present among regions, those in Scandinavia showing the smallest relative amplitude. The first insulin injection was given the same day or the day after diagnosis in $93 \%$ of the cases for whom data were available. [Diabetologia (1995) 38: 823-830]

Key words Childhood IDDM, seasonability, age of onset.
Wide variation in the incidence of childhood insulindependent diabetes mellitus (IDDM) has been reported in European countries [1]. Many studies have described age distributions of newly-diagnosed cases of childhood IDDM in Europe [2-12], but to our knowledge, no attempt has been made to compare the age distributions in high- and low-risk areas. If the age distribution varies with the population risk of IDDM, this might imply that different risk factors

* For complete list of centres please see acknowledgements

Received: 29 June 1994 and in revised form: 10 January 1995

Corresponding author: Dr. C. Lévy-Marchal, Service de Diabétologie, Hôpital Robert Debré, 48 Boulevard Sérurier, F75019 Paris, France

Abbreviations: IDDM, Insulin-dependent diabetes mellitus. or patterns of age-specific susceptibility are operating in different areas.

Similarly, seasonality between age-groups in the clinical onset of this disease has been reported on regional or national bases. The results have beeen inconsistent, particularly concerning the under 5-year age-group $[8,10,13-15]$. This uncertainty could be a result of the small numbers of patients in most registries when considered individually.

By using a standard protocol in a large number of geographically well-defined regions throughout Europe in a common time frame, the EURODIAB ACE research network provides a useful opportunity to study these issues.Using data collected during the first 2 years of the study (1989-1990), this paper reports a comparative analysis of age-specific incidence rates and seasonality in the original 26 EURODIAB ACE study centres. 
Table 1. Incidence data from the 24 centres included in the EURODIAB ACE network (1989-1990)

\begin{tabular}{|c|c|c|c|c|c|}
\hline Study Centres & Code & Population base & Number of cases & $\begin{array}{l}\text { Standard. } \\
\text { incidence } \\
\text { rates } \\
\times 10^{-5} \times \text { year }^{-1}\end{array}$ & $\begin{array}{l}\text { Estimated } \\
\text { ascertainment } \\
\text { rate }(\%)\end{array}$ \\
\hline Belgium & $\mathrm{B}$ & 159257 & 32 & 10.1 & 100.0 \\
\hline Denmark & DK & 150558 & 68 & 21.9 & 99.0 \\
\hline Finland & FIN & 174822 & 151 & 42.8 & 100.0 \\
\hline Greece (Athens region) & GR 1 & 657302 & 122 & 8.9 & 99.3 \\
\hline Greece (5 northern regions) & GR2 & 122881 & 16 & 6.2 & 99.5 \\
\hline Hungary & $\mathrm{H}$ & 1610822 & 255 & 7.6 & 98.6 \\
\hline Israel & IL & 1446098 & 156 & 5.5 & 100.0 \\
\hline Italy (Lombardy) & I1 & 1392866 & 195 & 6.8 & 99.7 \\
\hline Italy (Lazio) & $\mathrm{I} 2$ & 894428 & 129 & 7.2 & 100.0 \\
\hline Norway & $\mathbf{N}$ & 382176 & 158 & 20.9 & 100.0 \\
\hline Poland ( 9 provinces) & PL1 & 1317864 & 167 & 6.2 & 100.0 \\
\hline Poland ( 3 cities) & PL2 & 872246 & 101 & 5.8 & 100.0 \\
\hline Portugal (3 regions) & $\mathrm{P}$ & 142916 & 25 & 8.5 & 91.0 \\
\hline Romania & $\mathbf{R}$ & 450086 & 47 & 5.1 & 100.0 \\
\hline Slovenia & SLO & 418239 & 56 & 6.5 & 100.0 \\
\hline Spain (Catalonia) & E & 1076278 & 299 & 12.7 & 94.8 \\
\hline U.K. (N. Ireland) & UK 1 & 395300 & 149 & 19.0 & 99.2 \\
\hline U.K. (Oxford region) & UK 2 & 502229 & 162 & 16.3 & 97.8 \\
\hline Total & & 16277225 & 3168 & & \\
\hline
\end{tabular}

\section{Subjects and methods}

Study populations. Twenty-six centres across Europe were able to fulfil the conditions for participation in EURODIAB ACE in the first 2 years of the study, 1989-1990. For the purpose of the present analysis three Portuguese centres were combined, giving a total of 24 geographically well-defined regions. Compared with our previous publication [1] we have revised our database by including a small number of additional cases (Table 1). Further, compared to the first analysis [1] more recent demographic estimates have been obtained from all regions, the oldest dating back to 1987 .

Case definition and ascertainment. Insulin-dependent diabetes was confirmed as idiopathic by a physician. Cases qualified for inclusion in the study if the date of the first insulin injection was before the 15th birthday and between 1 January 1989 and 31 December 1990, and if the child had a permanent address within the study region at the date of the first insulin injection.

In each case primary ascertainment was based on hospital records, together with notification from family practitioners and pædiatricians. The completeness of ascertainment was assessed on the basis of other independent sources such as social insurance, patient associations, summer camps for diabetic children or prescription registers. The completeness of ascertainment was estimated by the "capture-recapture" method [16] as more than $90 \%$ in all regions (Table 1).

Data collection. A manual specifying data definitions and a common case record sheet were prepared for the local investigators. Variables which were recorded included case and centre identification, gender, date of birth and dates of clinical diagnosis and first insulin injection. The age at diagnosis was ex- pressed in fully attained years. Data management took place at the Central Coordinating Office (Odense, Denmark).

\section{Statistical analysis}

Incidence rates were expressed as the number of newly-diagnosed diabetic cases per 100,000 person-years, and were calculated for the age groups $0-4$ years, 5-9 years and 10-14 years. Directly standardised rates were calculated using a standard population comprising equal numbers in each of the six ageand sex-specific categories.

Poisson regression models [17] were used to study differences in age- and sex-specific incidence rates between regions. In this approach the age- and sex-specific incidence rates for each centre are predicted by a multiplicative model with terms representing sex, age-group and centre together with possible interactions between these variables. The adequacy of each model was assessed using a Chi-square test for goodness of fit. Likelihood ratio Chi-square tests were used to assess the significance of the terms in the model.

The method used to investigate seasonal variation assumed a sinusoidal pattern over the months of the year, with a peak and a nadir in incidence rates 6 months apart (Table 2) [18]. It provides a Chi-square statistic on 2 degrees of freedom, and is more reliable in small samples than the test originally described by Edwards [19]. The method also provides estimates of the time of the peak and of the relative amplitude of the seasonal component. It was also adapted for use with the Poisson regression model, making possible a test for heterogeneity of the fitted patterns of sinusoidal variation in subgroups of the data defined by sex, age-group and study centre (details available from authors on request). 
$0-4$ years

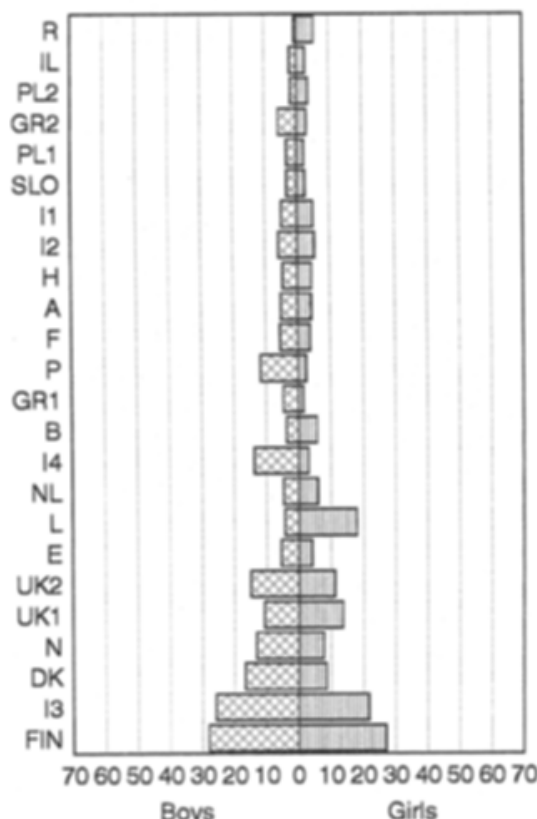

Boys
5-9 years

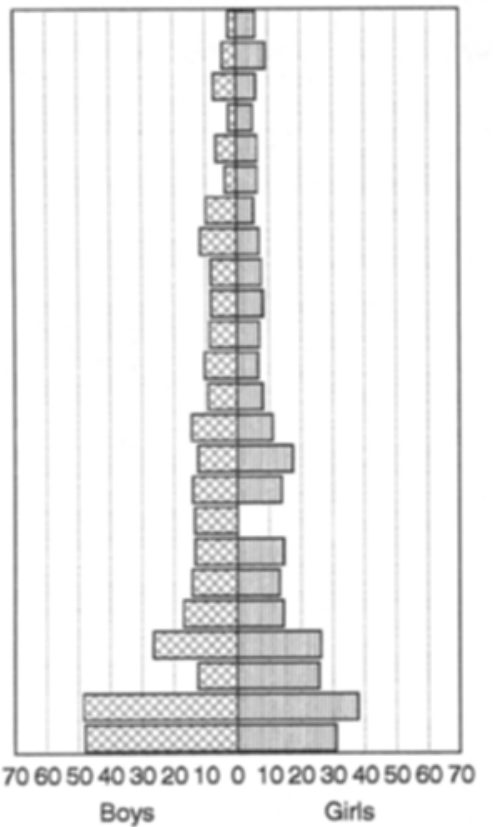

10-14 years

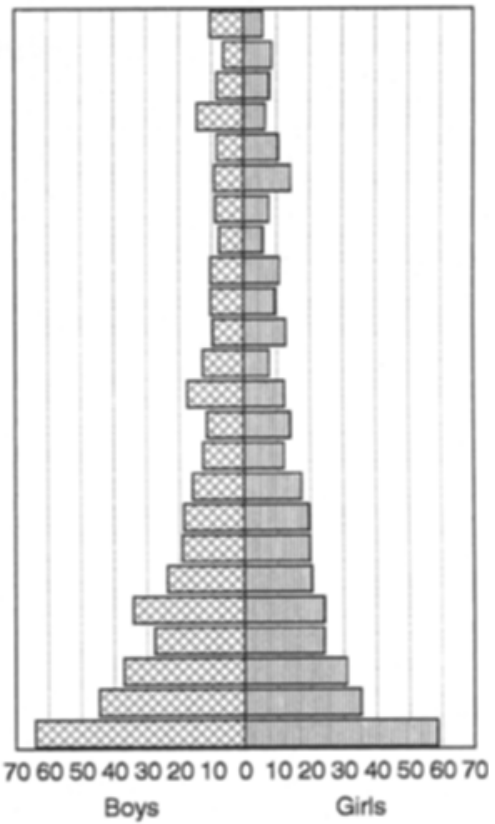

Incidence rate per 100,000

Fig. 1 Age- and sex-specific incidence rates in the 24 EURODIAB ACE regions. Incidence rates are expressed per 100,000 person-years. Countries are ranked according to the

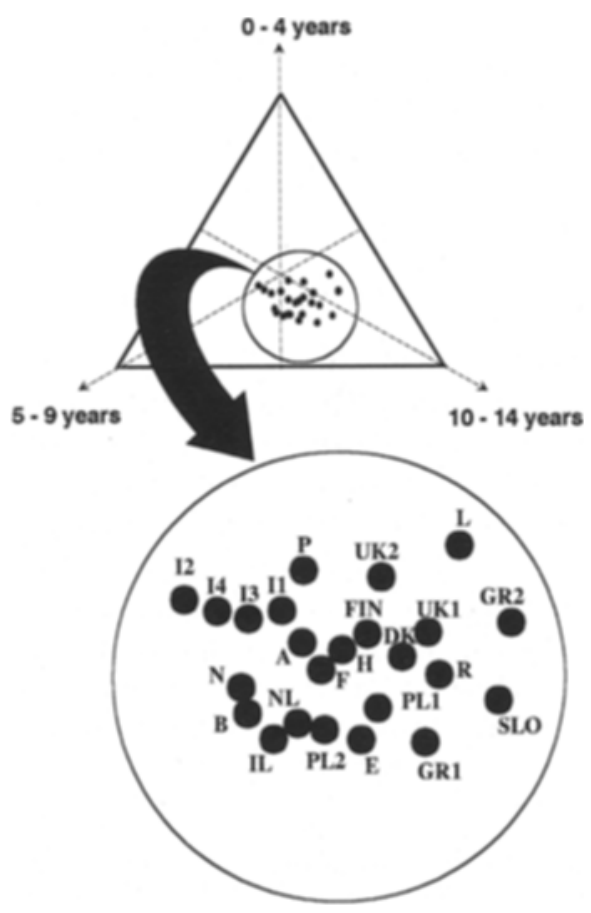

Fig. 2 Triangular representation of age-specific incidence in the 24 EURODIAB $A C E$ regions. Incidence rates in the three age groups $(0-4,5-9,10-14$ years $)$ are represented pictorially for the 24 regions [20]. Each age group is assigned to the vertex of a triangle. The 24 regions are plotted so that the higher the incidence rate in a given age group (relative to the other two age groups), the closer the point is to the relevant vertex. Three axes (one for each age group) are therefore represented in the triangle ascending standardized incidence rate. Abbreviations for the EURODIAB ACE centres are indicated in Table 1

\section{Results}

Overview of material. A total of 3,168 newly-diagnosed cases were identified in the 24 regions during the 2-year study period. There were 1,670 boys and 1,498 girls, giving a sex ratio in incidence rate (boys:girls) of 1.05 (95\% confidence interval $=0.98-$ 1.13). Table 1 shows the population base, the number of cases and the standardized incidence rate by region. The final column shows the estimated ascertainment rate. The standardised incidence rates varied between 5.1 per 100,000 per year in Romania to 42.8 per 100,000 per year in Finland.

Age-specific incidence rates. Eighteen percent of cases were aged $0-4$ years at diagnosis, $34 \%$ were aged 5-9 years and $48 \%$ were $10-14$ years.

Age- and sex-specific incidence rates in the 24 regions are presented in Figure 1 with regions sorted in ascending order of standardised incidence rate.

Poisson regression analysis of the age- and sex-specific incidence rates indicated that, after taking account of age and sex distribution of the study populations, there was a highly significant difference in incidence rates between the 24 regions (likelihood ratio test $\left.\chi^{2}=958.4 ; d f=23 ; p<0.001\right)$. There was no evidence that the sex ratio differed between the 24 regions (likelihood ratio test for sex by centre interaction $\left.\chi^{2}=30.1 ; d f=23 ; p=0.15\right)$. However, there was a significant age-by-region interaction (likelihood ra- 
Table 2. Analysis of the seasonal variation in incidence according to a sinusoidal model

\begin{tabular}{|c|c|c|c|c|c|c|}
\hline $\begin{array}{l}\text { Study } \\
\text { centre }\end{array}$ & Code & $\begin{array}{l}\text { Cases } \\
(n)\end{array}$ & $\begin{array}{l}\chi^{2} \\
(d f=2)\end{array}$ & $p$ value & $\begin{array}{l}\text { Relative } \\
\text { amplitude }\end{array}$ & $\begin{array}{l}\text { Peak } \\
\text { month }\end{array}$ \\
\hline Austria & A & 203 & 4.3 & & $\pm 22 \%$ & \\
\hline Belgium & B & 32 & & & & \\
\hline Denmark & DK & 68 & & & & \\
\hline Finland & FIN & 151 & 1.4 & & $\pm 13 \%$ & \\
\hline France & $\mathrm{F}$ & 261 & 8.0 & $<0.05$ & $\pm 25 \%$ & January \\
\hline Greece (Athens region) & GR 1 & 122 & 1.6 & & $\pm 18 \%$ & \\
\hline Greece (N. region) & GR2 & 16 & & & & \\
\hline Hungary & $\mathrm{H}$ & 156 & 6.5 & $<0.05$ & $\pm 29 \%$ & December \\
\hline Israel & IL & 255 & 20.4 & $<0.001$ & $\pm 42 \%$ & December \\
\hline Italy (Lombardy) & I1 & 195 & 12.6 & $<0.01$ & $\pm 38 \%$ & December \\
\hline Italy (Lazio) & $\mathrm{I} 2$ & 129 & 13.5 & $<0.01$ & $\pm 53 \%$ & March \\
\hline Italy (Sardinia) & I3 & 222 & 11.5 & $<0.01$ & $\pm 35 \%$ & January \\
\hline Italy (eastern Sicily) & I4 & 52 & & & & \\
\hline Luxemburg & $\mathrm{L}$ & 16 & & & & \\
\hline The Netherlands & NL & 126 & 8 & $<0.05$ & $\pm 36 \%$ & February \\
\hline Norway & $\mathbf{N}$ & 158 & 0.12 & & $\pm 2 \%$ & \\
\hline Poland ( 9 provinces) & PL1 & 167 & 10.5 & $<0.01$ & $\pm 38 \%$ & November \\
\hline Poland ( 3 cities) & PL2 & 101 & 2.2 & & $\pm 21 \%$ & \\
\hline Portugal (3 regions) & $\mathbf{P}$ & 25 & & & & \\
\hline Romania & $\mathbf{R}$ & 47 & & & & \\
\hline Slovenia & SLO & 56 & & & & \\
\hline Spain (Catalonia & $\mathrm{E}$ & 299 & 13.8 & $<0.01$ & $\pm 30 \%$ & February \\
\hline U.K. (N. Ireland) & UK 1 & 149 & 6.9 & $<0.05$ & $\pm 34 \%$ & January \\
\hline U.K. (Oxford region) & UK 2 & 162 & 11.6 & $<0.01$ & $\pm 37 \%$ & January \\
\hline
\end{tabular}

tio test $\chi^{2}=76.5 ; d f=46 ; p=0.003$ ) suggesting that the relative incidence rates in the three age groups were not uniform but varied from region to region. Only when this age-by-region interaction was included in the model was a satisfactory fit to the data obtained (goodness of fit $\chi^{2}=80.5 ; d f=69 ; p=0.16$ ).

To further investigate the nature of this age-byregion interaction, the 24 sets of age-specific rates (boys and girls combined) were plotted in a triangular axis system. Three axes are constructed through the vertices of an equilateral triangle, each axis representing the relative incidence rate in one of the three age groups. The method is outlined in Appendix 1, and further details are given elsewhere [20]. Regions are plotted in the triangle in such a way that the higher the incidence rate in one age-group relative to the other two, the closer to the corresponding vertex is the plot. It is thus possible to avoid the use of a more complex three-dimensional plot for which visual interpretation is difficult. The resulting diagram (Fig. 2) shows that most of the regions are plotted closest to the 10-14 years vertex since this age group tended to have the highest incidence rates. The plot suggested that most of the variation in incidence rates between regions paralleled the 10-14 years "axis", particularly if the two smallest regions (L and GR2) were disregarded. The four Italian regions appeared to be characterised by relatively low incidence rates in the 10-14 year age group, but otherwise, no consistent pattern emerged. The pattern implies that the region-to-region was similar for the 0-
4 and 5-9 year age groups, whereas the pattern of variation in the 10-14 year age group was different. The conclusion was further supported by the fitting of another Poisson regression model in which terms representing the interaction between age group and region were combined for the $0-4$ and 5-9 year age groups without significant loss of fit $\left(\chi^{2}=31.8 ; d f=23\right.$; $p=0.10$ ).

Seasonality at diagnosis. Seasonality for date of first insulin injection was examined for the 16 regions in which the number of cases exceeded 100. Data for both years, for boys and girls were combined in this analysis. In addition to the test of significance for seasonal variation, Table 2 shows the estimated relative amplitude of the seasonal component for each centre. The month of peak incidence is also shown for the 11 regions in which the test for seasonality was significant. All these regions showed peaks in winter or early spring (December through March). A test for heterogeneity in the seasonal variation, between the 16 regions was significant $\left(\chi^{2}=58.0 ; d f=30\right.$; $p=0.002)$. The observed and fitted patterns of seasonal variation are shown for each of the 16 regions in Fig.3. Although the sinusoidal pattern captured the seasonal variation well in many regions, in others (e.g., the two Scandinavian regions) the fit was less satisfactory.

Seasonal variation was also examined by year of study, by gender and by age-group. The pattern was similar for boys and girls and for the years 1989 and 

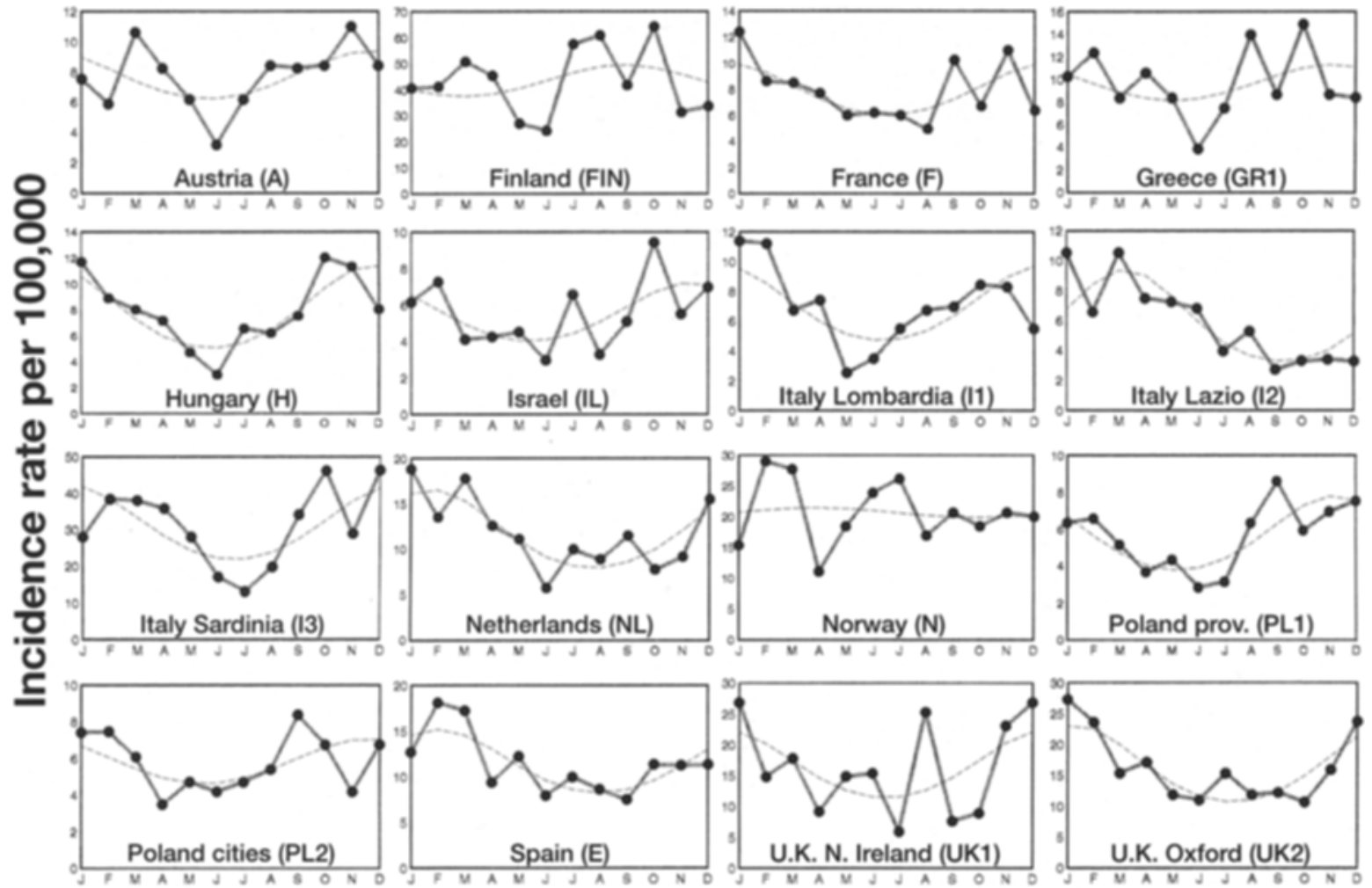

Month

Fig. 3 Seasonality at diagnosis by region. Incidence rates are plotted along the $y$ axis for each of the 16 regions where the number of cases exceeded 100. The $x$ axis represents

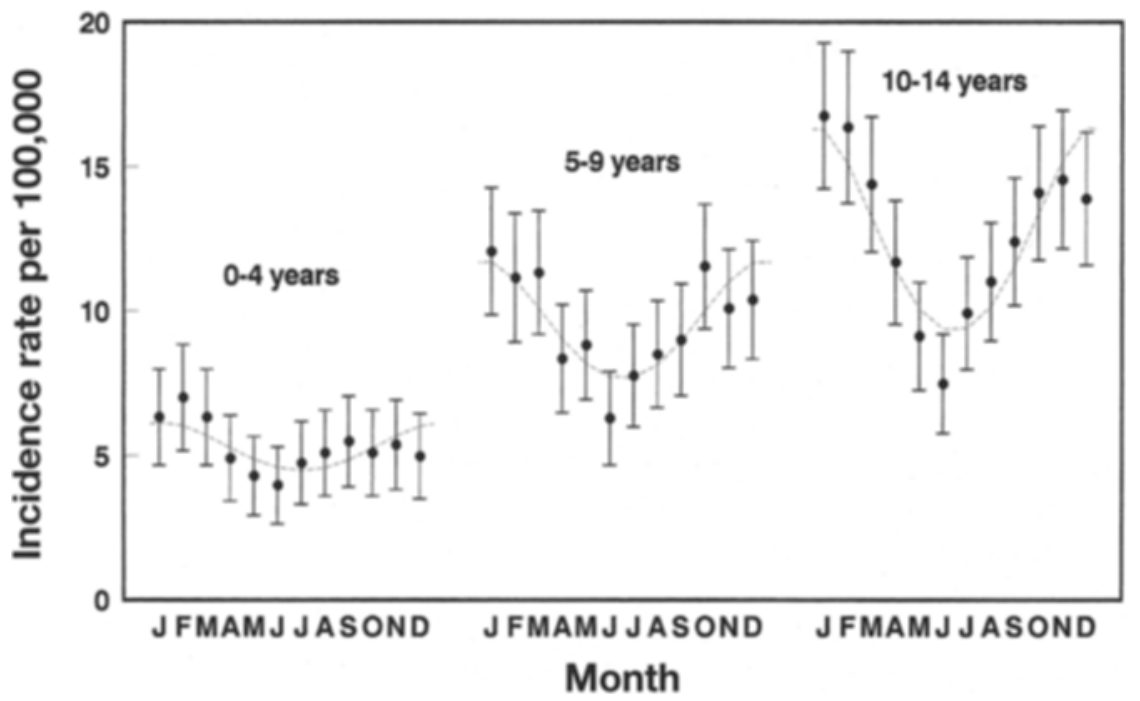

the months of the year, 1989 and 1990 combined. The solid lines represent the observed values; the dotted lines represent the fitted sinusoidal trends
1990. In each of the three age-groups significant seasonality was apparent with peak incidence occurring in December or January (Fig. 4). The relative amplitude increased with age being $\pm 16 \%$ in those aged $0-4$ years, $\pm 22 \%$ in those aged $5-9$ years and $\pm 29 \%$ in those aged 10-14 years. However, a test for heterogeneity in seasonal variation between the three age groups was not significant $\left(\chi^{2}=4.47 ; d f=4 ; p=0.35\right)$.
Fig.4 Seasonality at diagnosis according to age groups. Incidence rates and $95 \%$ confidence intervals are plotted on the $y$ axis. Month of diagnosis is represented on the $x$ axis, 1989 and 1990 combined. The dotted lines represent the fitted sinusoidal trends
Interval between diagnosis and first insulin injection. The first insulin injection was given the same day or the day after clinical diagnosis in $93 \%$ of the cases for whom data were available. In less than $1 \%$ this difference exceeded 1 month. This pattern was uniform across study regions (data not shown). 


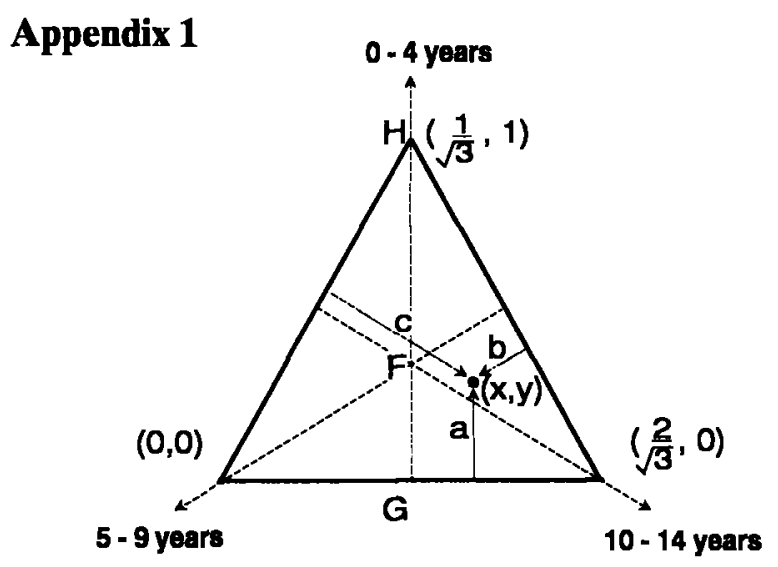

A centre which has rates $r_{1}, r_{2}$ and $r_{3}$ in the 0-4, 5-9 and 10-14 year age-groups, respectively, may be depicted in the above equilateral triangle as the point $(x, y)$ whose co-ordinates are

$\mathrm{x}=\frac{1-\mathrm{b}+\mathrm{c}}{\sqrt{3}} \quad \mathrm{y}=\mathrm{a}$

where $a=\frac{r_{1}}{r_{1}+r_{2}+r_{3}}, b=\frac{r_{2}}{r_{1}+r_{2}+r_{3}}$ and $c=\frac{r_{3}}{r_{1}+r_{2}+r_{3}}$

The distances between the point $(x, y)$ and the three sides of the triangle are $a, b$ and $c$ and are therefore in proportion to the rates. This presentation is therefore equivalent to plotting the centres on three axes defined by the relative magnitudes of the incidence rates in the three age groups. The larger is the incidence rate in one age-group relative to the other two, the closer will the point $(x, y)$ lie to the corresponding vertex of the triangle.

To illustrate the technique, consider the following examples.

If $r_{1}=r_{2}=r_{3}$, then $x=1 / \sqrt{3}$ and $y=1 / 3$, so the centre is plotted at $\mathrm{F}$.

If $r_{1}=0$ and $r_{2}=r_{3}$, then $x=1 / \sqrt{3}$ and $y=0$, so the centre is plotted at $\mathrm{G}$.

If $r_{1}=r$ and $r_{2}=r_{3}=0$, then $x=1 / \sqrt{3}$ and $y=1$, so the centre is plotted at $\mathrm{H}$.

\section{Discussion}

The registers from which results are reported in this study cover about $16 \%$ of all European children [21] with representation from most countries. Coupled with the high level of ascertainment, we believe that our analysis provides a reliable picture of the variation by age and seasonality across European populations.

The age distribution as illustrated in Figure 1 is similar to many previously reported studies with a relatively high incidence level in the age class around puberty [2-12]. Nevertheless, we found that $18 \%$ of the newly-diagnosed children are aged less than 5 years, which is a higher proportion than previously reported in several regional incidence studies in Europe. In a Swedish prospective incidence study, it has recently been shown that the increase by time during the 15-year study period was mainly due to an increase in incidence of children younger than 10 years [22]. Such a pattern is not evident from our results (Fig.2). Although incidence rates in the $0-4$ year and 5-9 year age ranges vary from region to region in a similar fashion, the pattern of variation in the older age group is different without a consistent pattern. Since the ascertainment rate is at least $95 \%$ in almost all regions, this observation seems to reflect a real phenomenon and not merely to reflect reduced ascertainment in some regions or in the older age group.

A possible explanation relates to the atiology of the disease. It has been suggested that the preclinical phase of IDDM extends over months or years with multiple environmental insults triggering successive autoimmune attacks. Some of these factors may have a more severe or rapid effect during puberty than they do in younger children. Exposure to some of these may also vary geographically.

Our study confirms the well-known seasonality of IDDM at diagnosis as originally described by Gamble et al. [23] and confirmed in many subsequent reports. Our analysis has identified two important additional features. Firstly, in contrast to some reports $[8,10,13-$ 15], seasonal variation at presentation is apparent even in the youngest age group, and across all European populations. Secondly, seasonal variation in diagnosis with a winter peak seems to be a characteristic in most European populations, including Southern Europe. This effect is not the same in all regions but varies geographically and possibly also with age (Fig.4). The effect of seasonality is least evident in the Scandinavian regions. It is possible that, in highrisk populations, many different factors unrelated to the initial trigger of the disease process may influence the timing of the clinical onset of diabetes. Seasonality appears to exert a weaker effect in this situation.

Variation in seasonality has been shown to be associated with HLA suceptibility markers. Patients with DR4 have been reported to have had a wider seasonal variation than those with DR3 [24-26]. If the genetic markers are a major determinant of seasonality, an association between seasonality and background incidence in Europe would suggest that HLA susceptibility is not evenly distributed among European patients with diabetes. More information is needed on the distribution of susceptible and protective genetic markers in diabetic and background populations with various levels of incidence of the disease.

To our knowledge, this is the first time that it has been demonstrated on an epidemiologically-sound basis that the date of the first insulin injection can be taken as a good approximation to the date of clinical onset of childhood IDDM. This applies to populations regardless of their population risk level of IDDM and can accordingly be recommended as an operational definition of time of IDDM onset. 
This study has shown that the variation in incidence of IDDM across Europe is associated with some unexplained heterogeneity in age distribution and in seasonality. It therefore seems that the contribution of environmental factors and the nature of the autoimmune process may not be the same in populations with different genetic determinants. More information is needed, not only from diabetic populations at diagnosis, but also from background populations in different parts of Europe. The EURODIAB ACE framework is currently addressing the issues of the contribution of genetic and non-genetic determinants to the ætiology and epidemiology of this disease.

Acknowledgements. This work was partly supported by a BIOMED grant (BMH-CT92-0003) from the European Community. Expert secretarial assistance was provided by Ms. G. Brutti, Odense.

EURODIAB ACE STUDY CENTRES: Austria, Dr. E. Schober (study leader), Dr. G. Ullreich, Universitäts Kinderklinik, Wien; Belgium (Antwerp region), Dr. C. Vandewalle (study leader), Belgian Diabetes Registry, Brussels; Denmark (3 regions), Dr. A. Svendsen (study leader), Genetic Epidemiology Research Unit, Odense University, Odense; Finland (2 regions), Dr. R. Lounamaa (study leader), Dr. J. Tuomilehto, Department of Epidemiology, National Public Health Institute and Dr. H.K. Åkerblom, Children's Hospital, Helsinki; France (4 regions), Prof. P. Czernichow (study leader), Dr. C. Levy-Marchal, Dr. C. de Beaufort, Dr. J. Doutreix, Dr. J. Voirin, Service d'Endocrinologie et Diabetologie Pédiatrique, Hôpital Robert Debré, Paris; Greece (Athens region), Dr. C.S. Bartsocas (study leader), Dr. C. Dakou-Voutetakis, Dr. S. Pantelakis, Dr. H. Theodoridis, Dr. K. Kassiou, the Greek Collaborative Group, "P.\&A. Kyriakou" Children's Hospital, Athens; Greece (Kilkis region), Dr. N. Papazoglou (study leader), Dr. C. H. Manes, Dr. E. Papadeli, Dr. G. Scaragas, Dr. N. Gotsis, Thessaloniki; Hungary (18 counties), Dr. G. Soltesz (study leader), Department of Pediatrics University Medical School of Pecs and the Hungarian Childhood Diabetes Epidemiology Group, Pecs; Israel, Dr. Z. Laron (study leader), Dr. O. Gordon, Dr. T. Shohat, Institute of Pediatric and Adolescent Endocrinology, Beilinson Medical Center, Petah Tikva; Italy (Lombardy), Dr. G. Chiumello (study leader), Dr. E. Bognetti, Dr. F. Meschi, Dr. C. Malavasi, Dr. E. Balzano, Clinica Pediatrica III Instituto Scientifico H San Raffaele, Milano; Italy (Lazio), Dr. P. Pozzilli (study leader), Dr. N. Visalli, Dr. A. Suppa, Dr. A. Guglielmi, Dr. M. L. Sebastiani, Endocrinologia (I) and Instituto Igiene, Universita di Roma "La Sapienza", Roma; Italy (Sardinia), Dr. M. Songini (study leader), Dr. M. Loche, Prof. M. Silvetti, Dr. E. Angius, The Sardinian Collaborative Group of Epidemiology of IDDM, Centro Malattie Dismetaboliche Ospedale San Michele, Cagliari; Italy (eastern Sicily), Dr. F. Purrello (study leader), Dr. M. Arpi, Dr. S. Italia, Dr. L. Tomaselli, Dr. M. Mancuso, Department of Endocrinology Ospedale Garibaldi, Catania; Luxembourg, Dr. C. de Beaufort (study leader), Dr. G. Michel, Dr. R. Wirion, Clinique Pédiatrique, $\mathrm{CH}$ de Luxembourg, Luxembourg; Netherlands (5 régions), Dr. M. Reeser (study leader), Juliana Children's Hospital, Gravenhage; Norway (8 counties), Dr. G. Joner (study leader), Department of Pediatrics, Aker University Hospital, Oslo; Dr. R.O. Sovik, Department of Pediatrics, Haukeland University Hospital, Bergen; Poland (9 regions), Dr. D. Woznicka (study leader), Dr. M. Walczak, Dr. G. Woz- nicki, Dr. W. Stankiewicz, Dr. A. Kedzia, Institute of Pedatrics, 3rd Clinic, Academy of Medicine in Poznan, Poznan; Poland (3 cities), Dr. Z. Szybinski (study leader), Dr. A. Czyzyk, Dr. R. Wasik, Department of Endocrinology, Institute of Medicine, Academy of Medicine in Cracow; Portugal (Madeira), Dr. S. Abreu (study leader) Centro Hospitalar do Funchal, Unidade de Endocrinologia, Funchal, Madeira; Portugal (Portalegre), Dr. C. Menezes (study leader), Servico de Medicina Interna, Consulta de Diabetes, Hospital Distrital de Portalegre, Portalegre; Portugal (Algarve), Dr. E. Pina (study leader), Servico de Medicina, Hospital Distrital de Faro, Faro; Romania (Bucharest), Dr. C. Ionescu-Tirgoviste (study leader), Dr. C. Dragomirescu, Dr. A. Nicolau, Clinic of Diabetes, Spitalul Cantacuzino, Bucharest; Slovenia, Dr. C. Krzisnik (study leader), Dr. T. Battelino, Dr. N. Bratanic, Department of Endocrinology, Diabetes and Metabolic Diseases, University Department of Pediatrics, Ljubljana; Spain (Catalonia), Dr. A. Goday (study leader), Servicio de Endocrinologia, Hospital del Mar, Barcelona, Dr. C. Castell, Dr. R. Tresserras, Dr. J.L. Taberner, Dr. G. Lloveras, Consell Assessor sobre la Diabetis a Catalunya, Departament de Sanitat, Generalitat de Catalunya; UK (Northern Ireland), Dr. D. Hadden (study leader), Dr. C. Patterson, Dr. D. Carson, Metabolic Unit, Royal Victoria Hospital, Belfast; UK (Oxford), Dr. P. Bingley (study leader), Department of Diabetes and Metabolism, St. Bartholomew's Hospital, London.

Members of EURODIAB project management group were: Dr. J. Fuller (London). Dr. E. Eschwege (Paris), Dr. E. A.M. Gale (London), Dr. A. Green (Odense), Dr. J. Nuñes-Correa (Lisbon), Dr. B. Karamanos (Athens), Dr. L. Papoz (Paris), Dr. G. Pozza (Milan), Dr. R. Williams (Cambridge). Members of EURODIAB ACE steering committee were: Dr. E. A. M. Gale (London), Dr. A. Green (Odense), Dr. C. Levy-Marchal (Paris), Dr. R. Lounamaa (Helsinki), Dr. G. Soltesz (Pecs), Dr. M. Songini (Cagliari).

\section{References}

1. Green A, Gale EAM, Patterson CC for the EURODIAB ACE Study Group (1992) Incidence of childhood-onset insulin-dependent diabetes mellitus: the EURODIAB ACE study. Lancet 339: 905-909

2. Joner G, Søvik O (1989) Increasing incidence of diabetes mellitus in Norwegian children 0-14 years of age 19731982. Diabetologia 32: 79-83

3. Drykoningen CEM, Mulder ALM, Vaandrager GJ, La Porte RE, Bruining GJ (1992) The incidence of male childhood type 1 diabetes (insulin-dependent) mellitus is rising rapidly in The Netherlands. Diabetologia 35: 139-142

4. Nyström L, Dahlquist G, Rewers M, Wall S (1990) The Swedish childhood diabetes study. An analysis of the temporal variation in diabetes incidence 1978-1987. Int J Epidemiol 19: 141-146

5. Tuomilehto J, Lounamaa $\mathrm{R}$, Tuomilehto-Wolf $\mathrm{E}$ et al. (1992) Epidemiology of childhood diabetes mellitus in Finland-background of a nationwide study of type 1 (insulindependent) diabetes mellitus. Diabetologia 35: 70-76

6. Lévy-Marchal C, Papoz L, de Beaufort C et al. (1990) Incidence of type 1 (insulin-dependent) diabetes mellitus in France. Diabetologia 33: 465-469

7. Green A, Hougaard P (1983) Epidemiological studies of diabetes mellitus in Denmark: 4. Clinical characteristics of insulin-treated diabetes. Diabetologia 25: 231-234

8. Patterson CC, Smith PG, Webb J, Heasman MA, Mann JI (1988) Geographical variation in the incidence of diabetes 
mellitus in Scottish children during the period 1977-1983.

Diabet Med 5: 160-165

9. Rewers M, Laporte RE, Walczak M, Dmochowski K, Bogaczynska E (1987) Apparent epidemic of insulin-dependent diabetes mellitus in midwestern Poland. Diabetes 36: 106-113

10. Schober E, Frisch H (1988) Incidence of childhood diabetes mellitus in Austria 1979-1984. Acta Paedr Scand 77: 299-302

11. Pagano G, Cavallo-Perrin P, Cavalot $P$ et al. (1987) Genetic, immunologic and environmental heterogeneity of IDDM. Incidence and 12-month follow-up of an Italian population. Diabetes 36: 859-863

12. Bingley PG, Gale EAM (1989) Incidence of diabetes mellitus in England: a study in the Oxford region, 1985-6. Br Med J 298: 558-560

13. Green A, Andersen PK, Svendsen AJ, Mortensen K (1992) Increasing incidence of early onset type 1 (insulin-dependent) diabetes: a study of Danish male birth cohorts. Diabetologia 35: 178-182

14. Joner G, Søvik O (1981) Incidence, age at onset and seasonal variation of diabetes mellitus in Norwegian children, 1973-1977. Acta Paedr Scand 70: 329-335

15. Dahlquist G, Gustavsson KH, Holmgren G et al. (1982) The incidence of diabetes mellitus in Swedish children 0-14 years of age. A prospective study 1971-1980. Acta Paedr Scand 71: 7-14

16. Bishop YMM, Fienberg SE, Holland PW (1974) Discrete multivariate analysis: theory and practice. MIT Press, Cambridge Mass.
17. Holford TR (1980) The analysis of rates and of survivorship using loglinear models. Biometrics 36: 299-305

18. Roger JH (1977) A significance test for cyclic trends in incidence data. Biometrika 64: 152-155

19. Edwards JH (1961) The recognition of cyclic trends. Ann Hum Gen 25: 83-85

20. Habbema JF, Hilden J, Bjerregaard B (1978) The measurement of performance in probabilistic diagnosis. I. The problem, descriptive tools, and measures based on classification matrices. Meth Inform Med 17: 217-226

21. World health statistics annual. World Health Organisation, Geneva, 1992, pp C5

22. Dahlquist G, Hustonen L (1994) Analysis of a 15-year prospective incidence study of childhood diabetes onset. Time trends and climatological factors. Int $\mathrm{J}$ Epidemiol 23: 1234-1241

23. Gamble DR (1980) The epidemiology of insulin-dependent diabetes with particular reference to the relationship of virus infection to its etiology. Epidemiol Rev 2: 49-70

24. Eberhardt MS, Wagener DK, Orchard TJ et al. (1985) HLA heterogeneity of insulin-dependent diabetes mellitus at diagnosis? The Pittsburgh IDDM study. Diabetes 34: $1247-1254$

25. Ludvigsson J, Samuelsson U, de Beaufort C et al. (1986) HLA-DR3 is associated with a more slowly progressive form of type 1 diabetes. Diabetologia 29: 207-210

26. Weinberg CR, Dorman TL, Hansen JA, Raghu PK, Palmer JP (1984) HLA-related heterogeneity in seasonal patterns of diagnosis in type 1 (insulin-dependent) diabetes. Diabetologia 26: 199-202 